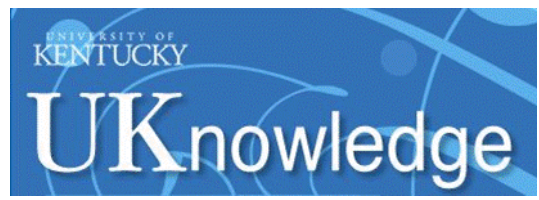

University of Kentucky

UKnowledge

\title{
Predictors of the Change in the Expression of Emotional Support within an Online Breast Cancer Support Group: A Longitudinal Study
}

\author{
Woohyun Yoo \\ University of Wisconsin-Madison \\ Ming-Yuan Chih \\ University of Wisconsin-Madison, m.chih@uky.edu \\ Min-Woo Kwon \\ University of Wisconsin-Madison \\ Junghwan Yang \\ University of Wisconsin-Madison \\ Eunji Cho \\ University of Wisconsin-Madison \\ Follow this and additional works at: https://uknowledge.uky.edu/cld_facpub \\ Part of the Communication Technology and New Media Commons, Community-Based Research \\ Soe next page for additional authors \\ Right click to open a feedback form in a new tab to let us know how this document benefits you.
}

\section{Repository Citation}

Yoo, Woohyun; Chih, Ming-Yuan; Kwon, Min-Woo; Yang, Junghwan; Cho, Eunji; McLaughlin, Bryan; Namkoong, Kang; Shah, Dhavan V.; and Gustafson, David H., "Predictors of the Change in the Expression of Emotional Support within an Online Breast Cancer Support Group: A Longitudinal Study" (2013). Community \& Leadership Development Faculty Publications. 3.

https://uknowledge.uky.edu/cld_facpub/3

This Article is brought to you for free and open access by the Community \& Leadership Development at UKnowledge. It has been accepted for inclusion in Community \& Leadership Development Faculty Publications by an authorized administrator of UKnowledge. For more information, please contact UKnowledge@lsv.uky.edu. 
Predictors of the Change in the Expression of Emotional Support within an Online Breast Cancer Support Group: A Longitudinal Study

Digital Object Identifier (DOI)

https://doi.org/10.1016/j.pec.2012.10.001

Notes/Citation Information

Published in Patient Education and Counseling, v. 90, issue 1, p. 88-95.

Copyright (C) 2012 Elsevier Ireland Ltd.

This manuscript version is made available under the CC-BY-NC-ND 4.0 license

http://creativecommons.org/licenses/by-nc-nd/4.0/.

Authors

Woohyun Yoo, Ming-Yuan Chih, Min-Woo Kwon, Junghwan Yang, Eunji Cho, Bryan McLaughlin, Kang Namkoong, Dhavan V. Shah, and David H. Gustafson 


\title{
Predictors of the change in the expression of emotional support within an online breast cancer support group: A longitudinal study
}

\author{
Woohyun Yoo ${ }^{\mathrm{a},{ }^{*}}$, Ming-Yuan Chih $^{\mathrm{b}}$, Min-Woo Kwon ${ }^{\mathrm{a}}$, JungHwan Yang ${ }^{\mathrm{a}}$, Eunji Cho ${ }^{\mathrm{a}}$, Bryan \\ McLaughlin $^{\mathrm{a}}$, Kang Namkoong ${ }^{\mathrm{c}}$, Dhavan V. Shah ${ }^{\mathrm{a}, \mathrm{b}}$, and David H. Gustafson ${ }^{\mathrm{b}}$ \\ aSchool of Journalism and Mass Communication, University of Wisconsin, Madison, USA \\ ${ }^{b}$ Center for Health Enhancement Systems Studies, University of Wisconsin, Madison, USA \\ 'Department of Community and Leadership Development, University of Kentucky, Lexington, \\ USA
}

\section{Abstract}

Objectives-To explore how the expression of emotional support in an online breast cancer support group changes over time, and what factors predict this pattern of change.

Methods-We conducted growth curve modeling with data collected from 192 participants in an online breast cancer support group within the Comprehensive Health Enhancement Support System (CHESS) during a 24-week intervention period.

Results-Individual expression of emotional support tends to increase over time for the first 12 weeks of the intervention, but then decrease slightly with time after that. In addition, we found that age, living situation, comfort level with computer and the Internet, coping strategies were important factors in predicting the changing pattern of expressing emotional support.

Conclusions-Expressing emotional support changed in a quadratic trajectory, with a range of factors predicting the changing pattern of expression.

Practical implications-These results can provide important information for e-health researchers and physicians in determining the benefits individuals can gain from participation in should CMSS groups as the purpose of cancer treatment.

\section{Keywords}

Expression effects; Computer-mediated social support (CMSS) group; Comprehensive Health Enhancement; Support System (CHESS); Breast cancer; Latent Growth Curve (LGC) modeling

\section{Introduction}

Breast cancer is one of the most frequently diagnosed cancers among American women [1]. To cope with a variety of cancer-related concerns [2-4], breast cancer patients have increasingly participated in computer-mediated social support (CMSS) groups[5-7]. These groups provide a venue for women with breast cancer to discuss their medical conditions,

(C) 2012 Elsevier Ireland Ltd. All rights reserved.

*Corresponding author at: 5050 Vilas Communication Hall, 821 University Ave, Madison, WI 53706, USA. Tel.: +1 6086300264. wyoo3@wisc.edu. .

Conflict of interest Authors have no conflicts of interest to report. 
share personal experiences, and exchange social support with those who share similar problems [8-10].

In particular, the expression of emotional support is a prevalent communication behavior within CMSS groups [11]. Expressing emotional support online can reduce breast cancerrelated concerns [12] and lead to more positive coping strategies [13]. It also increases patients' perceived bonding, and in turn, has beneficial impacts on coping strategies [14]. Although the effects of emotional expression are wide-reaching, little is known about how the expression of emotional support changes over the course of CMSS group engagement. Patients' participation in CMSS groups tends to vary from time to time $[4,15,16]$.

Additionally, CMSS group are dynamic, not static, as group members often come and go. Emotional support expression may be particularly likely to change over time because active participation requires more investment than passive reception of support messages, often referred to as "lurking." This study therefore explores how the expression of emotional support in a CMSS group for women with breast cancer changes over time, and what factors might predict emotional support expression over the long haul and which factors may eventually lead to decline in expressive participation.

\subsection{Changing pattern in the expression of emotional support}

Participants may initially be hesitant to engage in CMSS group discussion as online relationships often require more time to develop than face-to-face relationships $[17,18]$. Additionally, before participants express feelings of caring, concern, sympathy, and empathy, they may need some time to share experiences and develop a sense of mutual understanding [19]. Therefore, emotional support expression in CMSS groups is likely to be relatively low at the beginning of an intervention, but may grow over time. Alternatively, there may be group members who frequently express emotional support initially, but for various reasons tend to become less engaged as time goes on. It may be that factors that are highly predictive of emotional support expression early on are not predictive of continued active participation. Because CMSS groups are highly dynamic, it is important to learn more about the patterns of emotional expression and who stands to benefit most from participation over the long run.

\subsection{Potential predictors of the change in the expression of emotional support}

1.2.1. Socio-demographics-Socio-demographic factors likely play an essential role in the patterns of emotional support expression. Older women often adjust better to breast cancer compared to younger women [20-25]. Expressing emotional support is an effective way of adjusting to a life-threatening illness and thus, suggesting older patients' are likely to express more emotional support initially. Education level may also be an important predictor, as more educated breast cancer patients tend to be more expressive than less educated patients [26]. Hence, they are more likely to post emotional support messages early on. Finally, an individual's living situation, whether they live alone or with families/friends, should play an important role in patient's expression of emotional support. Those patients who live alone tend to post more messages in CMSS groups [27,28] because they have greater motivation to express their thoughts due to the lack of communication with family members.

While these socio-demographic factors may initially make it more probable that a participant is expressive, it may be that those who are not likely to engage initially eventually become more comfortable doing so. Alternatively, those who are initially comfortable may see less of a need to stay engaged over the long run. Accordingly, these factors must be considered on a longitudinal basis rather than simply considering the amount of expression that occurs. 
1.2.2. Disease-related factors-Although breast cancer patients experience a range of relatively common disease-related events, the point at which they experience these events differs. Individuals may be more or less likely to express emotional support depending on how recently they have been diagnosed and the treatments they have received. Cancer patients who have recently been diagnosed do not have much interest in CMSS groups because they are stressed and over-whelmed at that time [16]. Similarly, recently-diagnosed breast cancer patients tend to be lurkers who do not actively post messages [29]. The expression of emotional support is therefore likely influenced by how recently a breast cancer patient has been diagnosed or received surgical treatment.

1.2.3. Comfort level with computer and the Internet-Breast cancer patients who feel more competent using computers and the Internet also tend to feel more comfortable engaging in CMSS groups [30]. Therefore, they may be expected to post more messages upon entry into a support system. In contrast, low computer and Internet self-efficacy can lead to an initial hesitancy to provide emotional support [16]. Once a person has begun to integrate into a CMSS group, however, their level of comfort with a computer may begin to play a different role in their engagement, calibrating their levels of participation.

1.2.4. Coping strategies-Coping is defined as "efforts to prevent or diminish threat, harm, and loss or to reduce associated distress" [31] and it can be categorized into approach and avoidance coping strategies [32]. Approach coping strategies have the potential to predict supportive participation in an online environment. Patients with approach coping exhibit high self-esteem and therefore have more control in dealing with their illness $[33,34]$. Therefore, they tend to help others with a similar health problem in CMSS groups. Kim et al. [27] found approach coping was a positive predictor of expressing emotional support in CMSS groups. In conclusion, approach coping may continue to predict the expression of emotional support over time.

Alternatively, avoidance coping strategies have been linked to increased psychological distress for breast cancer patients [35-37]. While some avoidance coping strategies may initially help a patient adjust to their situation, long-term use of the avoidance coping strategies tends to distract the patient from addressing their problems and taking action to move forward [38]. As times goes by, avoidance coping, therefore, discourages participation in CMSS groups. It may also be, however, that engagement in CMSS groups may change a participant's coping behaviors, which, in turn, may change their likelihood of expressing emotional support.

\subsection{Research questions}

Based upon the above discussion, we aim to explore how emotional support expression changes for breast cancer patients in CMSS groups and which predictors may influence these changes over time. While numerous studies have examined the factors that predict initial engagement in CMSS groups, few studies have investigated the changing pattern of emotional support expression. Because CMSS groups are not static, it may be that the influence of these various factors changes over time. Further, given the dearth of research examining the long-term influence of these variables, we advance the following research questions rather than hypotheses.RQ1: How does the expression of emotional support change in a CMSS group for breast cancer patients over time?RQ2: What factors predict the changing pattern of expressing emotional support in a CMSS group for breast cancer patients? 


\section{Method}

\subsection{Participants}

The data analyzed in this study were collected as a part of a larger randomized clinical trial [39] assessing the effective elements of interactive cancer communication system called CHESS (the Comprehensive Health Enhancement Support System) for women with breast cancer. Recruitment for the experiment occurred from April 1, 2005, to May 31, 2007, at the University of Wisconsin, Hartford Hospital (Connecticut), and MD Anderson (Texas).

The CHESS system provides three kinds of services: (1) information, (2) interactive coaching, and (3) communication. To explore which types of services of CHESS benefit breast cancer patients, 661 women diagnosed with breast cancer were recruited and randomized to one of six experimental conditions: (1) Internet only, (2) CHESS information, (3) CHESS information and communication, (4) full CHESS (information, coaching, and communication), (5) Mentor only (human cancer information mentor), and (6) full CHESS + mentor. We only used data from three conditions in which participants had access to the CMSS group (CHESS information and communication, full CHESS, and full CHESS + -mentor). The CMSS group was a text-based, asynchronous bulletin board that allowed users to anonymously share information andsupport. Of the 325 participants, 192 women wrote at least one message $(M=26.38, S D=59.41)$ in the CMSS group during the sixmonth study period. Thus, 192 participants were included in the subsequent analyses examining expressions of emotional support.

\subsection{Procedures}

Emotional support is defined as the expression of following constructs: understanding, empathy, reassurance, concern, physical affection, relationship, and sympathy, encouragement, and universality [40-45]. To help facilitate coding, we grouped these components of emotional support into four larger subcategories: (1) empathy and sympathy refer to the cognitive understanding of another person's situation and feelings, (2) encouragement and reassurance provide the recipient with hope and confidence, (3) care and physical affection offer physical contact (e.g., hugs, kisses, hand-holding, and shoulder patting), (4) universality and relationships emphasize the importance of closeness, bonding and love in relationship with the recipient. After defining these subcategories, we developed dictionaries of keywords associated with these subcategories (see Table 1). These categories were then collapsed to create an "emotional support" construct.

Using the keyword dictionaries, a computer content analysis program, InfoTrend [46], was employed to analyze the expression of emotional support within 18,064 individual messages posted in the CMSS group. InfoTrend allows the user to code for key ideas and idea combinations in the text through the implementation of a dynamic rule structure $[47,48]$. More specifically, this program uses the computer language to enter (a) idea categories, (b) words that tap or reveal those idea categories, and (c) coding rules that allow pairs of ideas in the text to be combined to form more complex meaning. With these three components, human coders can create and refine the specific coding rules.

To examine the strength and complexity of our coding scheme, reliability estimates were conducted on a random subset of 200 discussion posts. Based on the reliability test of human and computer coding, there was an estimate of $91.0 \%$ agreement across the four different categories. Scott's pi [49] was calculated by comparing the percent of expected agreement by chance across the four coded categories with the actual agreement, which was determined to be $86.2 \%$ greater than by chance. 
Next, we integrated the emotional support message coding with action log and survey data in order to test relationship between predictors and emotional support expression. The action log data allowed us to match message board post with their authors, enabling us to track which participants wrote emotional support messages. That is, we were able to merge computer-aided content coding with the action log files indicating who had posted the message, merging the two to create a measure that captured both "who said what" and "when they said it."

\subsection{Analysis}

To answer our research questions, we used Latent Growth Curve (LGC) modeling within the framework of structural equation modeling (SEM). This approach enables us to study individual differences in the change of outcome variables over time and to determine the effects of potential predictors on the outcome change across time [50]. Mplus 6.1 [51] was used to estimate three different LGC models. Specifically, we first estimated the unconditional LGC model without predictors in order to examine the changing pattern the underlying individual differences at baseline and the rate of change over time in the expression of emotional support. The second LGC model was employed to evaluate the effects of time-invariant predictors on the changing pattern, both the initial status and the rate of change. The final LGC model was used to estimate the effects of a time-variant predictor on the expression of emotional support at 2, 6, 12, and 24 weeks following the commencement of the intervention.

\subsection{Measures}

2.4.1. Expression of emotional support-The primary outcome of this study is the expression of emotional support that was assessed at four time points during the intervention. Following previous research [12-14], emotional support expression was measured by the total count of emotional support categories divided by the total number of messages posted. Because there is significant variance among participants in the volume of messages written, this ratio offers a more accurate comparison than raw scores. Moreover, this measure helps rule out potential confounding effects of expressing other types of support [12]. Table 2 presents the descriptive statistics for the relevant components of the measurement.

2.4.2. Predictors-Potential predictors were divided into two categories according to methodological criteria: time-invariant predictors and time-variant predictors. Specifically, socio-demographics, disease-related factors, comfort level with computer and the Internet, and intervention conditions were tested as time-invariant predictors. All time-invariant predictors were measured at the baseline. Social and demographic characteristics included age, education, and living situation (live alone: no $=0$ and yes $=1$ ) and disease-related factors comprised past surgical experience (no $=0$ and yes $=1$ ) and days since diagnosis. Table 3 presents the demographic and clinical characteristics of the present study sample.

Comfort level with computer and the Internet was measured by two 5-point scale items using the following two questions: "How comfortable are you at using a computer?" and "How comfortable are you using the Internet?" The two items were averaged to create an index, with a higher score indicating higher comfort level $(M=2.99, S D=1.08$, inter-item $r$ $=.91$ ). Lastly, two experimental conditions (reference group: CHESS information and communication services only) were included in order to control the potential effects of the manipulation.

Approach and avoidance coping strategies were examined as time-variant predictors. To create an index of approach coping, we used the mean score of 4 approach coping subscales 
(active coping, planning, positive reframing, and humor) of the brief cope [38] ( $M=1.83$, $S D=.58$, Cronbach's $a=.74$ at pre-test; $M=1.81, S D=.59$, Cronbach's $a=.77$ at 2 weeks; $M=1.69, S D=.55$, Cronbach's $a=.74$ at 6 weeks; $M=1.64, S D=.60$, Cronbach's $a=.77$ at 12 weeks). Avoidance coping was measured by the mean score of 4 avoidance coping subscales (self-distraction, denial, behavioral disengagement, and self-blame) of the brief cope [38] ( $M=.78, S D=.43$, Cronbach's $a=.61$ at pre-test; $M=.67, S D=.36$, Cronbach's $a=.60$ at 2 weeks; $M=.67, S D=.38$, Cronbach's $a=.62$ at 6 weeks; $M=.64$, $S D=.36$, Cronbach's $a=.58$ at 12 weeks). Each subscale used to assess approach and avoidance coping was tapped on a 4-point measure ranging from 0 (I haven't been doing this at all) to 3 (I've been doing this a lot).

\section{Results}

\subsection{Change in the expression of emotional support}

As shown in Fig. 1, the percentage of the expression of emotional support in CMSS groups for breast cancer patients increased from 2 weeks to 12 weeks, but declined very slightly for the last 12 weeks. It can be seen that the expression of emotional support changed in a quadratic trajectory. An unconditional, quadratic LGC model was used to estimate the growth pattern of the expression of emotional support at 2, 6, 12, and 24 weeks. Overall the unconditional, quadratic model showed good model fit $\left(\chi^{2}=2.27(1), p=.13\right.$, RMSEA = . 07 , SRMR $=.02$, and CFI $=.99$ ). The estimated means of expressing emotional support was plotted as the blue line in Fig. 1.

Table 4 presents the results of the unconditional LGC model. The intercept of the expression of emotional support was $.200(p<.001)$, the linear slope was .063 $(p<.05)$, and the quadratic slope was $-.009(p<.05)$. Mean value of emotional support expression at 2 weeks was .200 and it increased at an average of .063 (the linear slope) up to 12 weeks, but decreased an average of .009 (the quadratic slope) after 12 weeks. In addition, the variance of the intercept factor was .088 $(p<.01)$, indicating significant individual differences in the expression of emotional support at 2 weeks. The variances of the linear slope and quadratic slope factors were $.097(p<.001)$ and $.002(p<.05)$, suggesting significant individual differences in the change of emotional support expression overtime.

\subsection{Effects of time-invariant predictors}

Considering that emotional support expression varied at 2 weeks and over time, a LGC model with time-invariant predictors was conducted to explore whether the time-invariant predictors were associated with individual differences at 2 weeks and whether they predicted changes in the expression of emotional support. Fig. 2 presents the LGC model of expressing emotional support including time-invariant predictors and the model fit the data well $\left(\chi^{2}=18.40(9), p=.03, \mathrm{RMSEA}=.07\right.$, SRMR $=.02$, and CFI $\left.=.96\right)$.

For this conditional model, the primary focus centers on the path coefficients leading from time-invariant predictors to the intercept and slopes. As shown in Table 5, age was positively associated with the intercept $(.45, p<.05)$, indicating that older patients had a higher level of the expression of emotional support at 2 weeks compared to younger patients. In addition, living alone was positively related to the intercept $(.18, p<.01)$, suggesting that patients living alone were more likely than those living with other to post messages of emotional support at 2 weeks. Comfort level with computer was positively associated with the linear slope $(.35, p<.01)$, but negatively related to the quadratic slope $(-.41, p<.01)$. For patients who feel comfortable using the computer and the Internet, emotional support expression increased more rapidly from weeks 2 to 12 , but it then decreased more significantly for the last 12 weeks. 


\subsection{Effect of time-variant predictors}

This study examined the effect of coping strategies as time-variant predictors by using a LGC model as shown in Fig. 3. The LGC model of emotional support expression including time-invariant and time-variant predictors resulted in very good fit indices $\left(\chi^{2}=32.99(33)\right.$, $p=.46$, RMSEA $=.00, \mathrm{SRMR}=.02$, and CFI $=1.00$ ). In this model, the results of timeinvariant predictors remained relatively similar to those from the LGC model of expressing emotional support with only time-invariant predictors.

Table 6 presents the effects of time-variant predictors on the expression of emotional support. Approach coping at previous time points was positively associated with the expression of emotional support at most next time points, excluding 2 weeks $(.21, p<.001$ at 6 weeks; .22, $p<.001$ at 12 weeks; .22, $p<.001$ at 24 weeks). This means that patients who had higher approach coping were more likely to post messages of emotional support through the subsequent intervention period. However, avoidance coping predicted the expression of emotional support at only 24 weeks such that avoidance coping at 12 weeks was negatively associated with the expression of emotional support at 24 weeks $(-.10, p<$. $05)$.

\section{Discussion and conclusion}

\subsection{Discussion}

This study sought to build on research that has demonstrated the importance of emotional support expression in CMSS groups, as well as studies that have detailed some of the factors that predict CMSS engagement habits for breast cancer patients. Specifically, we examined how the expression of emotional support changes over time and whether some potential factors predict these changes. The results of our study contribute two important findings. First, the expression of emotional support increased within the first 12 weeks of the intervention. Regarding the rise of emotional support expression, two interpretations can be suggested. From the group engagement model [52], the CMSS group facilitates a sense of group identity and then the patients' greater sense of identification with the group leads to more expression of emotional support over time. It is also possible that the reception of emotional support increases the expression of emotional support. Members of a social network have expectations for a reward or an intention to maintain the equilibrium of social support [53]. Accordingly, breast cancer patients who received emotional support are more likely to express emotional support in CMSS groups.

In contrast to this rise, after 12 weeks, we observed a decline in emotional support expression. Although such expression declined after the first 12 weeks of the intervention, the degree of the decrease was small. This slight decline likely reflects a ceiling effect rather than a notable drop in participation. These findings suggest that CMSS participants are initially hesitant to express emotional support, but become more expressive as they integrate within the group, maintaining this level until they hit a relative maximum, after which they plateau.

Second, our findings highlight some of the important predictors of emotional support expression over time. Initial expression of emotional support can be predicted by age or living status, as older women living alone were more likely to post emotional support messages at the beginning of the intervention. In addition, women with a higher level of comfort with computers and the Internet were more likely to post the messages of emotional support for the first 12 weeks of the intervention. More interestingly, they were less likely to post emotional support over time after 12 weeks. It may be that those who feel confident in navigating the Internet also feel more capable of moving on to other online resources. Thus, while those with high levels of computer proficiency may initially benefit from CMSS 
groups, it may be that they stand to gain less over the long term. Finally, coping strategies predicted the expression of emotional support differently over different time periods. Specifically, only approach coping was predictive of expressing emotional support by the middle of the intervention. However, avoidance coping strategies were predictive for the expression of emotional support at the end of the intervention.

On the other hand, one important limitation must be considered for future study. In this study, emotional support includes only four types of emotional support and thus, follow-up research should look at different components of emotional support.

\subsection{Conclusions}

In a CMSS group for women with breast cancer, the expression of emotional support increases over time during the mid of intervention, but decreases slightly with time after that. Among several potential time-invariant predictors, age, living situation, and the comfort level with computers and the Internet have significant relationships with this overtime tendency. As time-variant predictors, coping strategies are also found as the crucial determinant of expressing emotionally supportive message. These longitudinal patterns indicate individual variability.

\subsection{Practical implications}

The present study provides some important implications for health practitioners. As a longitudinal study, our findings present the changing pattern of the expression of emotional support in online breast cancer patients over time and what factors precede the change. The information is valuable in developing long-term e-health interventions. First, the e-health intervention period should be longer than 12 weeks, as cancer patients may participate more actively over time for 12 weeks after they join in the intervention. Second, health educators should consider training breast cancer patients on how to use computer and the Internet before they enter the intervention to ensure maximal expression. Moreover, they should emphasize usability and design process and consider employing various types of access devices such as mobile, tablet, laptop, and web-enabled TV devices. As a participant chooses a particular tool according to individual preference or comfort, the technological barrier to accessing e-health intervention may be removed to some extent. Third, e-health intervention managers should devise effective ways to encourage younger women and patients living alone to participate actively at the beginning of the intervention, potentially using prompts or follow-up calls. Finally, health educators should try to enhance breast cancer patients' approach coping and evade their avoidance coping in order to increase the expression of emotional support.

\section{Acknowledgments}

Role of the funding source This research was supported by P50 CA095817-05 from the National Cancer Institute. Study sponsors had no involvement in this research.

\section{References}

[1]. America Cancer Society. Cancer facts and figures. 2011. Available from: http://www.cancer.org/ acs/groups/content/@epidemiologysurveilance/documents/document/acspc-029771.pdf

[2]. Spiegel D. Psychosocial aspects of breast cancer treatment. Semin Oncol. 1997; 24:36-47.

[3]. Bleiker E, Pouwer F, van der Ploeg HM, Leer JWH, Adèr HJ. Psychological distress two years after diagnosis of breast cancer: frequency and prediction. Patient Educ Couns. 2000; 40:209-17. [PubMed: 10838000] 
[4]. Gustafson DH, McTavish FM, Stengle W, Ballard D, Hawkins R, Shaw BR, et al. Use and impact of e-Health system by low-income women with breast cancer. J Health Commun. 2005; 10:194218.

[5]. Han JY, Shaw BR, Hawkins RP, Pingree S, McTavish FM, Gustafson DH. Expressing positive emotions within online support groups by women with breast cancer. J Health Psychol. 2008; 13:1002-7. [PubMed: 18987072]

[6]. Shaw BR, Hawkins RP, McTavish FM, Pingree S, Gustafson DH. Effects of insightful disclosure within computer mediated support groups on women with breast cancer. Health Commun. 2006; 19:133-42. [PubMed: 16548704]

[7]. Shaw BR, Han JY, Kim E, Gustafson DH, Hawkins RP, Cleary J, et al. Effects of prayer and religious expression within computer support groups on women with breast cancer. Psychooncology. 2007; 21:531-40. [PubMed: 21416553]

[8]. Sharf BF. Communicating breast cancer on-line: support and empowerment on the Internet. Women Health. 1997; 26:65-84. [PubMed: 9311100]

[9]. van Uden-Kraan CF, Drossaert CH, Taal E, Shaw B, Seydel ER, van de Laar MA. Empowering processes and outcomes of participation in online support groups for patients with breast cancer, arthritis, or fibromyalgia. Qual Health Res. 2008; 18:405-17. [PubMed: 18235163]

[10]. Weinberg N, Schmale J, Uken JS, Wessel K. Online help: cancer patients participate in a computer. Health Soc Work. 1996; 21:24-9. [PubMed: 8626154]

[11]. Rodgers S, Chen Q. Internet community group participation: psychosocial benefits for women with breast cancer. J Comput Mediat Commun. 2005; 10 Available from:http://jcmc.indiana.edu/ vol10/issue4/rodgers.html.

[12]. Han JY, Shah DV, Kim E, Namkoong K, Lee SY, Moon TJ, et al. Empathic exchanges in online cancer support groups: distinguishing message expression and reception effects. Health Commun. 2011; 26:185-97. [PubMed: 21318917]

[13]. Kim E, Han JY, Moon TJ, Shaw BR, Shah DV, McTavish FM, et al. The process and effect of supportive message expression and reception in online breast cancer support groups. Psychooncology. 2012; 21:531-40. [PubMed: 21416553]

[14]. Namkoong, K.; Shah, DV.; McLaughlin, B.; Yoo, W.; Kim, SC.; Hull, S., et al. Computer mediated social support and the effects of expression: the mediating role of perceived bonding on cancer patients' coping strategies. Paper presented at annual conference of the association for education in journalism and mass communication conference; 2011.

[15]. Gustafson DH, Hawkins R, Pingree S, McTavish FM, Arora NK, Mendenhall J, et al. Effect of computer support on younger women with breast cancer. J Gen Intern Med. 2001; 16:435-45. [PubMed: 11520380]

[16]. Buss MK, DuBenske LL, Dinauer S, Gustafson DH, McTavish FM, Cleary JF. Patient/caregiver influences for declining participation in supportive oncology trials. J Support Oncol. 2008; 6:168-74. [PubMed: 18491685]

[17]. Hancock, JT.; Landrigan, C.; Silver, C. Expressing emotion in text-based communication. Paper presented at the proceedings of the SIGCHI conference on human factors in computing systems; 2007.

[18]. Walther, JB.; Boyd, S. Attraction to computer-mediated social support. In: Lin, CA.; Atkin, D., editors. Communicatin technology and society: audience adoption and uses. Hampton Press; Cresskill, NJ: 2002. p. 153-88.

[19]. Walther JB. Computer-mediated communication: impersonal, interpersonal, and hyperpersonal interaction. Commun Res. 1996; 23:3-43.

[20]. Bloom JR, Kessler L. Risk and timing of counseling and support interventions for younger women with breast cancer. J Natl Cancer Inst Monogr. 1994; 16:199-206. [PubMed: 7999465]

[21]. Cordova MJ, Andrykowski MA, Kenady DE, McGrath PC, Sloan DA, Redd WH. Frequency and correlates of posttraumatic-stress-disorder-like symptoms after treatment for breast cancer. $\mathrm{J}$ Consult Clin Psychol. 1995; 63:981-6. [PubMed: 8543720]

[22]. Ganz PA, Rowland JH, Desmond K, Meyerowitz BE, Wyatt GE. Life after breast cancer: understanding women's health-related quality of life and sexual functioning. J Clin Oncol. 1998; 16:501-14. [PubMed: 9469334] 
[23]. Harrison J, Maguire P. Influence of age on psychological adjustment to cancer. Psychooncology. $1995 ; 4: 33-8$.

[24]. Mor V, Allen S, Malin M. The psychosocial impact of cancer on older versus younger patients and their families. Cancer. 1994; 74:2118-27. [PubMed: 8087779]

[25]. Vinokur AD, Threatt BA, Vinokur-Kaplan D, Satariano WA. The process of recovery from breast cancer for younger and older patients: changes during the first year. Cancer. 1990; 65:1242-54. [PubMed: 2302673]

[26]. Street RL. Information-giving in medical consultations: the influence of patients' communicative styles and personal characteristics. Soc Sci Med. 1991; 32:541-8. [PubMed: 2017721]

[27]. Kim E, Han JY, Shah DV, Shaw BR, McTavish FM, Gustafson DH. Predictors of supportive message expression and reception in an interactive cancer communication system. J Health Commun. 2011; 16:1106-21. [PubMed: 22070449]

[28]. Han JY, Kim J-H, Yoon HJ, Shim M, McTavish FM, Gustafson DH. Social and psychological determinants of levels of engagement with an online breast cancer support group: posters, lurkers, and non-users. J Health Commun. 2012:356-71. [PubMed: 22085215]

[29]. van Uden-Kraan CF, Drossaert CHC, Taal E, Seydel ER, van de Laar MAFJ. Self-reported differences in empowerment between lurkers and posters in online patient support groups. J Med Internet Res. 2008; 10:e18. [PubMed: 18653442]

[30]. McDowell H, Kim E, Shaw BR, Han JY, Gumieny L. Predictors and effects of training on an online health education and support system for women with breast cancer. J Comput Mediat Commun. 2010; 15:412-26. [PubMed: 21949474]

[31]. Carver CS, Connor-Smith J. Personality and coping. Annu Rev Psychol. 2010; 61:679-704. [PubMed: 19572784]

[32]. Taylor SE, Stanton AL. Coping resources, coping processes, and mental health. Annu Rev Psychol. 2007; 3:377-401.

[33]. Aspinwall LG, Taylor SE. Modeling cognitive adaptation: a longitudinal investigation of the impact of individual differences and coping on college adjustment and performance. J Pers Soc Psychol. 1992; 63:989-1003. [PubMed: 1460565]

[34]. Grande GE, Myers LB, Sutton SR. How do patients who participate in cancer support groups differ from those who do not? Psychooncology. 2006; 15:321-34. [PubMed: 16106472]

[35]. Zabalegui A. Coping strategies and psychological distress in patients with advanced cancer. Oncol Nurs Forum. 1999; 26:1511-8. [PubMed: 11064882]

[36]. Hebert R, Zdaniuk B, Schulz R, Scheier M. Positive and negative religious coping and well-being in women with breast cancer. J Palliat Med. 2009; 12:537-45. [PubMed: 19508140]

[37]. Bussell VA, Naus MJ. A longitudinal investigation of coping and posttraumatic growth in breast cancer survivors. J Psychosoc Oncol. 2010; 28:61-78. [PubMed: 20391066]

[38]. Carver CS, Scheier MF, Weintraub JK. Assessing coping strategies: a theoretically based approach. J Pers Soc Psychol. 1989; 56:267-83. [PubMed: 2926629]

[39]. Baker TB, Hawkins RP, Pingree S, Roberts LJ, McDowell HE, et al. Optimizing eHealth breast cancer interventions: which types of eHealth services are effective? Transl Behav Med. 2011; 1:134-45. [PubMed: 21709810]

[40]. Braithwaite DO, Waldron VR, Finn J. Communication of social support in computer-mediated groups for persons with disabilities. Health Commun. 1999; 11:123-51. [PubMed: 16370973]

[41]. Coursaris CK, Liu M. An analysis of social support exchanges in online HIV/AIDS self-help groups. Comput Human Behav. 2009; 25:911-8.

[42]. Cutrona, CE.; Suhr, JA. Social support communication in the context of marriage: an analysis of couples' supportive interactions. In: Burleson, BR.; Albrecht, TL.; Sarason, IG., editors. Communication of social support. Sage; Thousand Oaks, CA: 1994. p. 113-35.

[43]. Cutrona CE, Suhr JA. Controllability of stressful events and satisfaction with spouse support behaviors. Communic Res. 1992; 19:154-74.

[44]. Rook, KS.; Underwood, LG. Social support measurement and interventions: comments and future directions. In: Cohen, S.; Underwood, LG.; Gottlieb, BH., editors. Social support measurement and intervention: a guide for health and social scientists. Oxford University Press; New York, NY: 2000. p. 311-34. 
[45]. Shaw BR, McTavish FM, Hawkins RP, Gustafson DH, Pingree S. Experiences of women with breast cancer: exchanging social support over the CHESS computer network. J Health Commun. 2000; 5:135-59. [PubMed: 11010346]

[46]. Fan DP. Ideodynamics: the kinetics of the evolution of ideas. J Math Sociol. 1985; 11:1-24.

[47]. Fan DP, Wyatt RO, Keltner K. The suicidal messenger: how press reporting affects public confidence in the press, the military, and organized religion. Communic Res. 2001; 28:826-52.

[48]. Shah DV, Watts MD, Domke D, Fan DP. News framing and cueing of issue regimes: explaining Clinton's public approval in spite of scandal. Public Opin Q. 2002; 66:339-70.

[49]. Scott W. Reliability of content analysis: the case of nominal scale coding. Public Opin Q. 1955; 19:321-5.

[50]. Duncan TE, Duncan SC. An introduction to latent growth curve modeling. Behav Ther. 2004; 35:333-63.

[51]. Muthén, LK.; Muthén, BO. Mplus user's guide. 6th ed. Muthén \& Muthén; Los Angeles, CA: 1998-2010.

[52]. Tyler TR, Blader SL. The group engagement model: procedural justice, social identity, and cooperative behavior. Pers Soc Psychol Rev. 2003; 7:349-61. [PubMed: 14633471]

[53]. Uehara E. Reciprocity reconsidered: Gouldner's moral norm of reciprocity and social support. J Pers Soc Relationships. 1995; 12:483-502. 

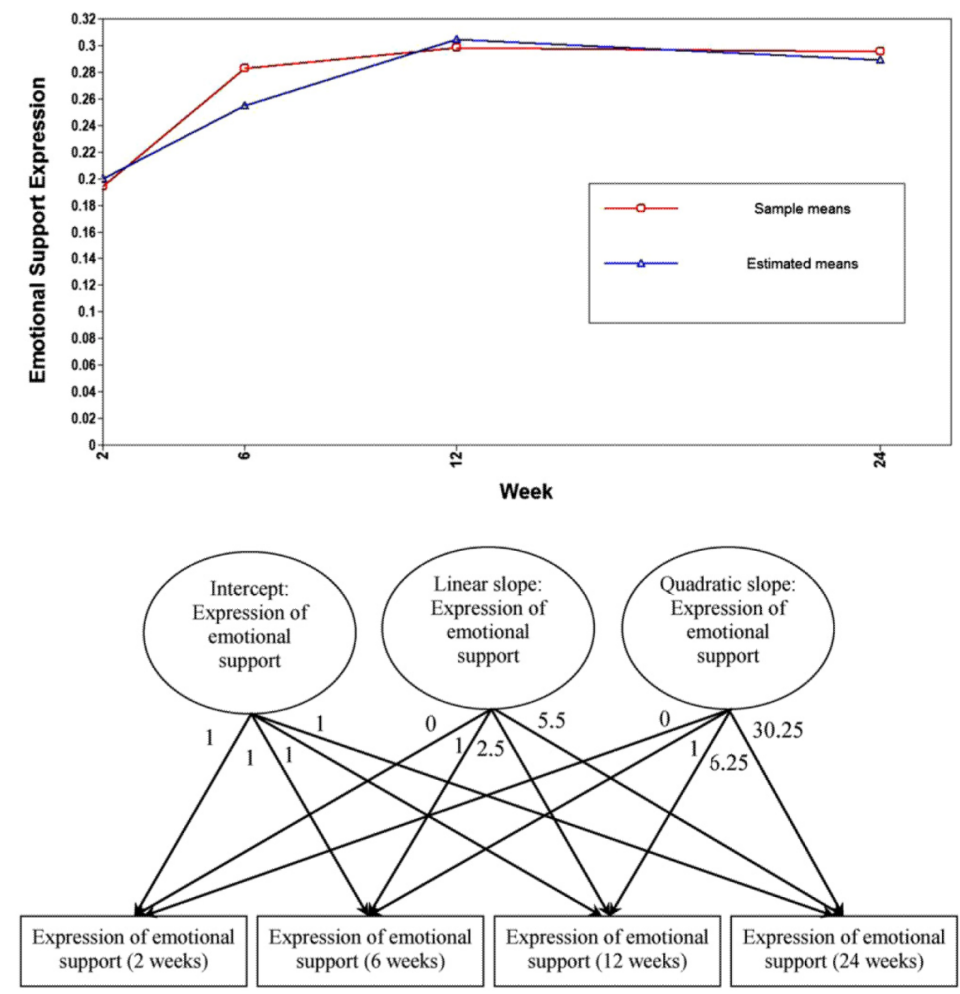

Fig. 1.

Line graphs and unconditional LGM model of the expression of emotional support from 2 weeks to 24 weeks $(N=192)$. Note: $\chi^{2}=2.27(1), p=.13$, RMSEA $=.07$, SRMR $=.02$, and $\mathrm{CFI}=.99$. 


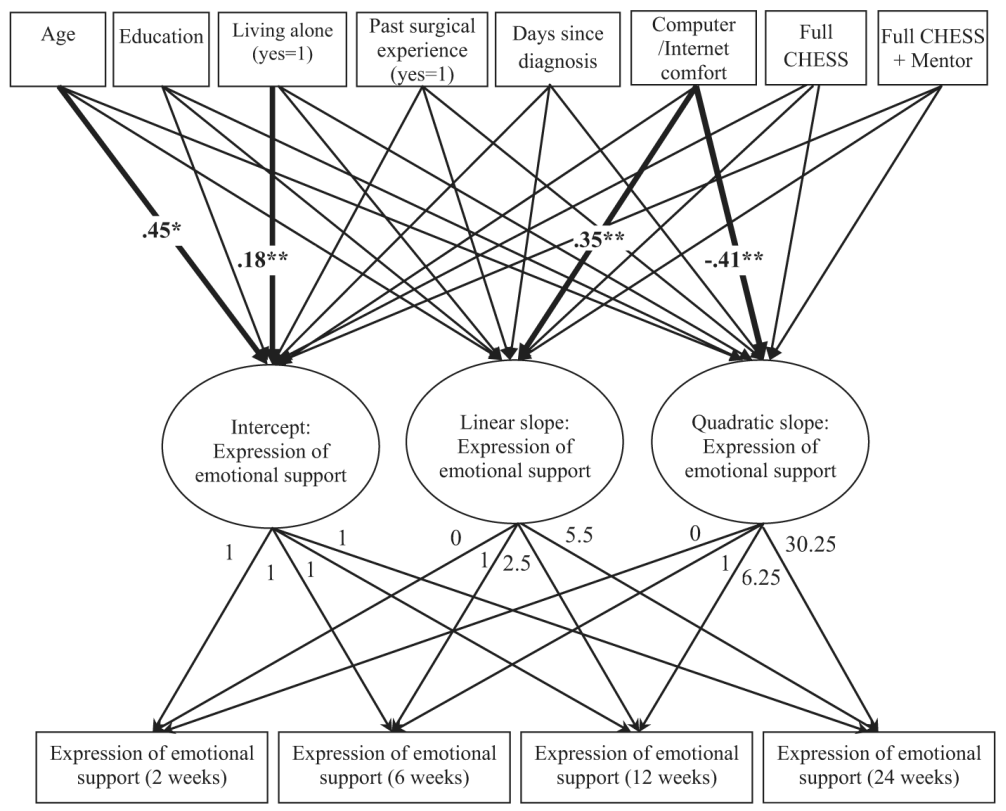

Fig. 2.

LGC model of the expression of emotional support from 2 weeks to 24 weeks with timeinvariant predictors $(N=192)$. Note: Bold lines indicate statistically significant paths with standardized coefficients. $\chi^{2}=18.40(9), p=.03, \mathrm{RMSEA}=.07, \mathrm{SRMR}=.02$, and CFI $=$. 96. $* p<.05, * * p<.01, * * * p<.001$. 


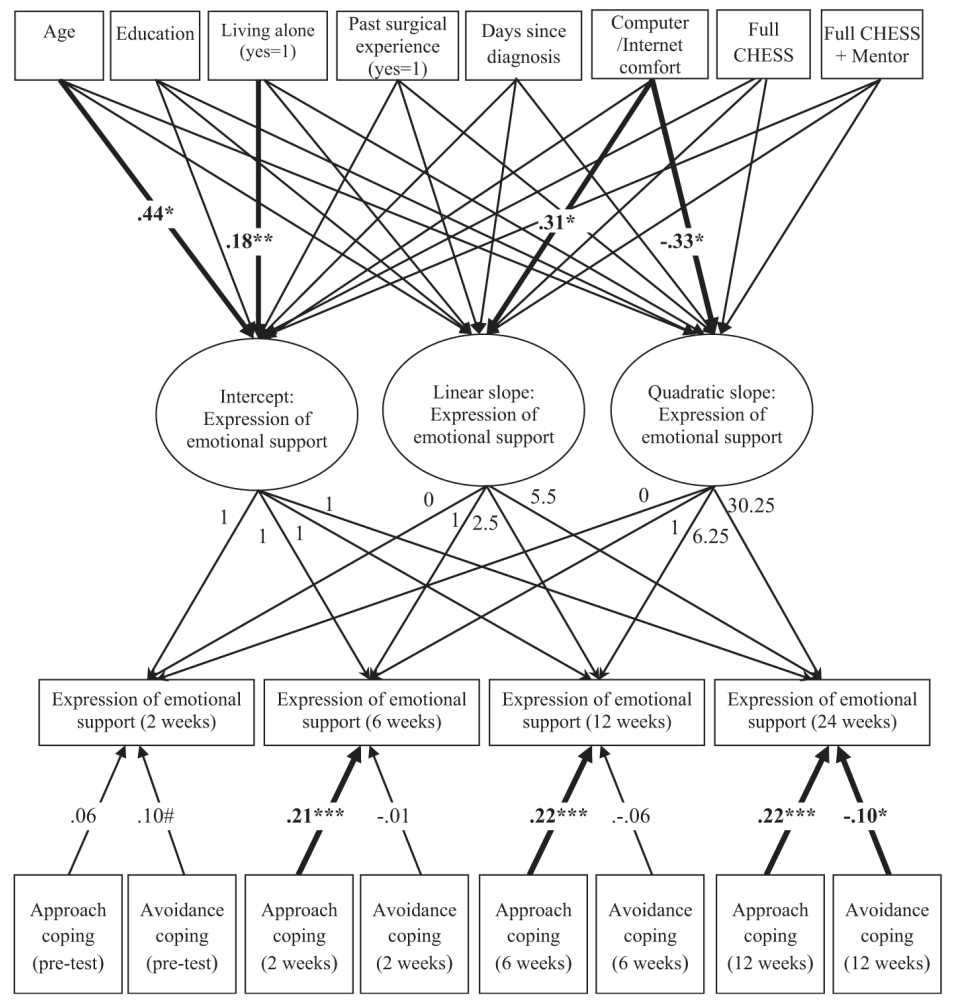

Fig. 3.

LGC model of the expression of emotional support from 2 weeks to 24 weeks with timeinvariant and time-variant predictors $(N=192)$. Note: Bold lines indicate statistically significant paths with standardized coefficients. $\chi^{2}=32.99(33), p=.46, \mathrm{RMSEA}=.00$, $\mathrm{SRMR}=.02$, and CFI $=1.00 . \# p<.10, * p<.05, * * p<.01, * * * p<.001$. 
Table 1

Subcategories of emotional support and keywords.

\begin{tabular}{ll}
\hline Emotional support & Keywords \\
\hline Empathy/sympathy & $\begin{array}{l}\text { Empathy, sympathy, understand, sorry, } \\
\text { worry, concern, etc. }\end{array}$ \\
Encouragement/reassurance & $\begin{array}{l}\text { Hope, wish, trust, congratulation, cheer, } \\
\text { hang in there, keep stay strong, } \\
\text { keep marching, don't give up etc. }\end{array}$ \\
Care/physical affection & $\begin{array}{l}\text { Take care, hugs, kisses, love, etc. } \\
\text { Universality/relationship }\end{array}$ \\
& $\begin{array}{l}\text { Common, isolated, army of chessling, } \\
\text { sisterhood, etc. not alone, together, etc. }\end{array}$ \\
\hline
\end{tabular}


Table 2

Descriptive statistics for CMSS group activities $(N=192)$.

\begin{tabular}{|c|c|c|c|c|c|c|c|c|}
\hline & \multicolumn{2}{|c|}{ 0-2 weeks } & \multicolumn{2}{|c|}{ 2-6 weeks } & \multicolumn{2}{|c|}{ 6-12 weeks } & \multicolumn{2}{|c|}{ 12-24 weeks } \\
\hline & $M$ & SD & $M$ & SD & $M$ & SD & $M$ & SD \\
\hline Total number of messages posted ${ }^{a}$ & 3.13 & 6.06 & 6.33 & 13.54 & 6.66 & 18.43 & 10.26 & 29.50 \\
\hline Expression of emotional support ${ }^{b}$ & .24 & .41 & .35 & .57 & .37 & .66 & .36 & .64 \\
\hline Empathy/sympathy ${ }^{b}$ & .01 & .03 & .02 & .06 & .02 & .05 & .02 & .09 \\
\hline Encouragement/reassurance ${ }^{b}$ & .07 & .20 & .16 & .33 & .18 & .36 & .17 & .31 \\
\hline Care/physical affection ${ }^{b}$ & .15 & .31 & .14 & .28 & .14 & .29 & .14 & .30 \\
\hline Universality/relationship $^{b}$ & .01 & .04 & .03 & .09 & .03 & .10 & .03 & .11 \\
\hline
\end{tabular}

Note: The statistics shown in the table represent values per participant.

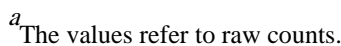

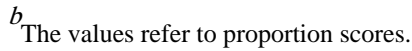




\section{Table 3}

Sample characteristics.

\begin{tabular}{lc}
\hline & Participants $(\boldsymbol{N}=\mathbf{1 9 2})$ \\
\hline Age & 51.42 \\
Mean (SD) & 09.08 \\
Education & \\
Some junior high & $02(1.1 \%)$ \\
Some high school & $04(2.1 \%)$ \\
High school degree & $29(15.3 \%)$ \\
Some college courses & $34(18.0 \%)$ \\
Associate degree & $20(10.6 \%)$ \\
Bachelor's degree & $49(25.9 \%)$ \\
Some graduate courses & $16(8.5 \%)$ \\
Graduate degree & $35(18.5 \%)$ \\
N/A & 3 \\
Living alone & \\
Yes & $27(14.1 \%)$ \\
No & $164(85.9 \%)$ \\
N/A & 1 \\
Past surgical experience & \\
Yes & $99(54.1 \%)$ \\
No & $83(45.4 \%)$ \\
N/A & 10 \\
Days since diagnosis & \\
Mean (SD) & $69.84(29.91)$ \\
\hline
\end{tabular}


Table 4

Results on unconditional LGC model of the expression of emotional support from 2 weeks to 24 weeks $(N=$ 192).

\begin{tabular}{lc}
\hline Effect & Robust maximum likelihood (MLR) \\
\hline Intercept & $.200^{* * *}$ \\
Linear slope & $.063^{*}$ \\
Quadratic slope & $-.009^{*}$ \\
Var (intercept) & $.088^{* *}$ \\
Var (slope) & $.097^{* * *}$ \\
Var (quadratic slope) & $.002^{*}$ \\
\hline$* \quad$ \\
$p<.05$. \\
$* * \quad p<.01$. \\
$\begin{array}{l}* * * \\
\quad p<.001 .\end{array}$
\end{tabular}


Table 5

Effects of time-invariant predictors on the expression of emotional support from 2 weeks to 24 weeks $(N=$ 192).

\begin{tabular}{lccc}
\hline Predictors & Intercept & $\begin{array}{c}\text { Linear } \\
\text { slope }\end{array}$ & $\begin{array}{c}\text { Quadratic } \\
\text { slope }\end{array}$ \\
\hline Age & $.45^{*}$ & -.18 & .15 \\
Education & -.09 & .01 & .03 \\
Living alone (yes = 1) & $.18^{* *}$ & -.06 & .09 \\
Computer/Internet comfort & .01 & $.35^{* *}$ & $-.41^{* *}$ \\
Past surgical experience (yes $=1)$ & -.004 & -.15 & .17 \\
Days since diagnosis & -.14 & .05 & -.02 \\
Full CHESS & .11 & .14 & -.14 \\
Full CHESS + mentor & .03 & .12 & -.13 \\
\hline
\end{tabular}

Note: Coefficients are standardized. All these effects result from the LGM model with time-invariant predictors as shown in Fig. 2.

* $p<.05$.

*** $p<.01$. 


\section{Table 6}

Effects of time-variant predictors on the expression of emotional support from 2 weeks to 24 weeks $(N=192)$.

\begin{tabular}{lcccc}
\hline Predictors & $\begin{array}{c}\text { Expression of } \\
\text { emotional } \\
\text { support (2 weeks) }\end{array}$ & $\begin{array}{c}\text { Expression of } \\
\text { emotional } \\
\text { support (6 weeks) }\end{array}$ & $\begin{array}{c}\text { Expression of } \\
\text { emotional } \\
\text { support (12 weeks) }\end{array}$ & $\begin{array}{c}\text { Expression of } \\
\text { emotional } \\
\text { support (24 weeks) }\end{array}$ \\
\hline Approach coping (pre-test) & .06 & - & - & - \\
Avoidance coping (pre-test) & $.10^{\#}$ & - & - & - \\
Approach coping (2 weeks) & - & $.21^{* * *}$ & - & - \\
Avoidance coping (2 weeks) & - & -.01 & $-22^{* * *}$ & - \\
Approach coping (6 weeks) & - & - & -.06 & $.22^{* * * *}$ \\
Avoidance coping (6 weeks) & - & - & - & $-.10^{*}$ \\
Approach coping (12 weeks) & - & - & - & - \\
Avoidance coping (12 weeks) & - & - & & \\
\hline
\end{tabular}

Note: Coefficients are standardized. All these effects result from the LGM model with time-invariant and time-variant predictors as shown in Fig. 3.

* $p<.05$.

$* * *$

$p<.001$.

${ }^{\#} p<.10$. 